\title{
Recent trends in management of bronchial asthma
}

\author{
${ }^{1}$ Ashraf E. Seleem, ${ }^{2}$ Hanan M. Elnahas, ${ }^{3}$ Ahmed Amin, ${ }^{4 *}$ Ahmed M. Goda.
}

${ }^{1}$ Department of Chest Diseases, Faculty of Medicine, ${ }^{2}$ Department of pharmaceutics, Faculty of Pharmacy, Zagazig University, Egypt. ${ }^{3}$ Department of Clinical Pharmacy, Faculty of Pharmacy, kafr ElSheikh University, Egypt. ${ }^{4}$ Department of Pharmacy Practice, Faculty of Pharmacy, Zagazig University, Zagazig, Egypt

*Corresponding author: Email: Dr.godaa@gmail.com,: Tel: 01000197337

Running Title: Asthma Management.

Received: 05 Feb 2021/Accepted: 09 May 2021 / Published online: 01 June 2021.

\begin{abstract}
Bronchial Asthma is the most common chronic inflammatory disease of lungs. The prevalence of asthma is increasing worldwide, and the disease possesses a substantial global health and economic burden. Asthma involves both the large and the small-conducting airways, and is characterized by a combination of inflammation and structural remodeling. Disease progression occurs in the context of a developmental background in which the postnatal acquisition of asthma is strongly linked with allergic sensitization. Most asthma cases follow a variable course, involving viral-induced wheezing and allergen sensitization, that is associated with various underlying mechanisms (or endotypes) that can differ between individuals. Each set of endotypes, in turn, produces specific asthma characteristics that evolve across the life course of the patient. Strong genetic and environmental drivers of asthma interconnect through novel epigenetic mechanisms that operate prenatally and throughout childhood. Asthma can spontaneously remit or begin de novo in adulthood, and the factors that lead to the emergence and regression of asthma, irrespective of age, are poorly understood. Nonetheless, there is mounting evidence that supports a primary role for structural changes in the airways with asthma acquisition, on which altered innate immune mechanisms and microbiota interactions are superimposed. On the basis of the identification of new causative pathways, the sub-phenotyping of asthma across the life course of patients is paving the way for more-personalized and precise pathway-specific approaches for the prevention and treatment of asthma, creating the real possibility of total prevention and cure for this chronic inflammatory disease.
\end{abstract}

Key words: Asthma, Asthma management, Inhaled corticosteroids, Bronchodilators, GINA

\section{Introduction}

\section{Definition of bronchial asthma}

The 2020 Global Strategy for Asthma Management and Prevention by the Global Initiative for Asthma (GINA) defined asthma as a heterogeneous disease characterized by chronic airway inflammation and variable remodeling that results in a range of clinical presentations, treatment responses and natural history across the life course of the patient(GINA, 2020).

\section{Symptoms of bronchial asthma}

Asthma involves a history of respiratory symptoms including wheeze, shortness of 
breath, chest tightness and cough that vary over time and in intensity, variable expiratory airflow limitation and airway hyperresponsiveness to a range of stimuli, such as exercise and inhaled irritants. At the population level, a subset of individuals with asthma exhibits an accelerated decline in lung function over their lifetime(Lange et al., 1998), which, in severe chronic disease, manifests as fixed airflow obstruction. This decline is especially prominent in late-onset asthma(Porsbjerg et al., 2015).

\section{Pathophysiology of bronchial asthma}

The origin and severity of asthma are driven by strong genetic and environmental factors (Figure 1).

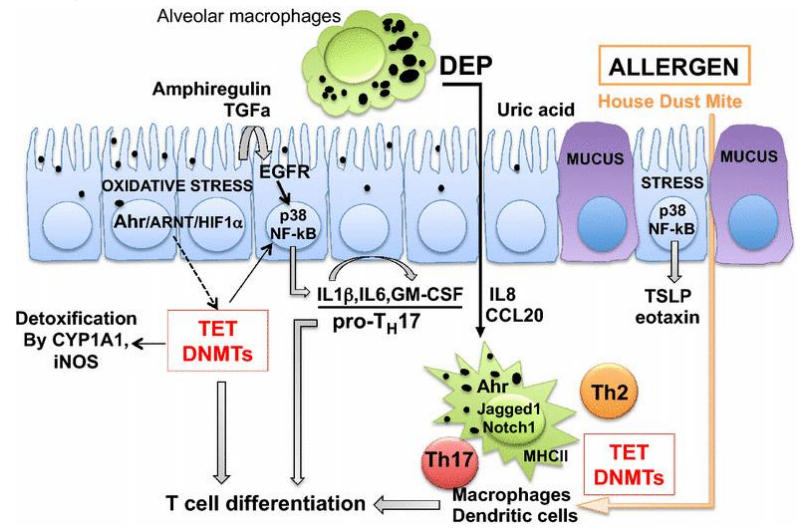

Figure 1: Epigenetic mechanisms mediate DEP (diesel exhaust particles) on asthma pathogenesis(Qian et al., 2020) DEP: Diesels exhaust particles

Although most cases of asthma begin in childhood in association with IgE-dependent sensitization to common environmental allergens(Custovic, 2015), asthma can also emerge later in life. Adult-onset asthma often occurs in the absence of allergy but can be accompanied by intolerance to NSAIDs, rhinosinusitis and nasal polyps(Amelink et al., 2013). Intolerance to NSAIDs most likely results from reduced production of the antibronco constrictor prostaglandin E2 under conditions of inflammation.

\section{Comorbidities of bronchial asthma}

Asthma is often accompanied by comorbidities including multi-organ allergies, such as allergic rhinitis, conjunctivitis, atopic dermatitis and food allergy, as well as nonallergic disorders, such as obesity, gastroesophageal reflux and psychiatric conditions(Ledford \& Lockey, 2013).

\section{Bronchial Asthma triggers factors}

Asthma is subject to periods of rapid deterioration (or exacerbations) that are provoked by viral infection and exposure to allergens, air pollutants and certain drugs such as aspirin and other NSAIDs(Custovic et al., 2013). In addition, certain types of asthma can enter spontaneous remission (that is, patients become symptom-free), such as during late childhood and adolescence( $\mathrm{Fu}$ et al., 2014), and can respond to allergen-specific immunotherapy through the acquisition of immunological tolerance(Soyka et al., 2014).

Pharmacological Management of bronchial asthma

In both adults and children, asthma has been traditionally classified by either symptom severity or the extent of disease control achieved using a stepwise management process, in which patients are grouped into one of four or five categories that are used to determine treatment requirements with controller drugs. These drugs include inhaled corticosteroids (ICSs), long-acting $\beta 2$-adrenergic receptor agonists (LABAs), long-acting muscarinic antagonists, leukotriene receptor antagonists (LTRAs) and, for the most severe disease, the IgE-specific monoclonal antibody omalizumab(Postma \& Rabe, 2015). Although this stepwise approach 
has improved the management of asthma and reduced dependency on inhaled short-acting bronchodilators (SABAs) for symptom relief, none of these treatments have been shown to alter the natural history of the disease(Murray et al., 2006). Cluster and other nonhierarchical analyses have identified subtypes of asthma phenotypes associated with differing causal pathways, natural histories and responses to interventions (Moore et al., 2010) (Figure $2 \& 3$ ).

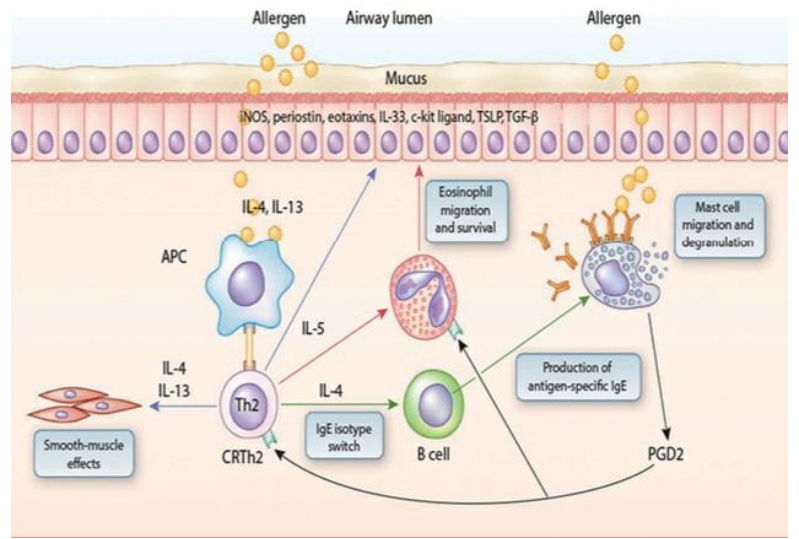

Figure 2: Bronchial asthma phenotypes (Th2 asthma phenotype) (Wenzel, 2006). Th2: Thelper cells type 2

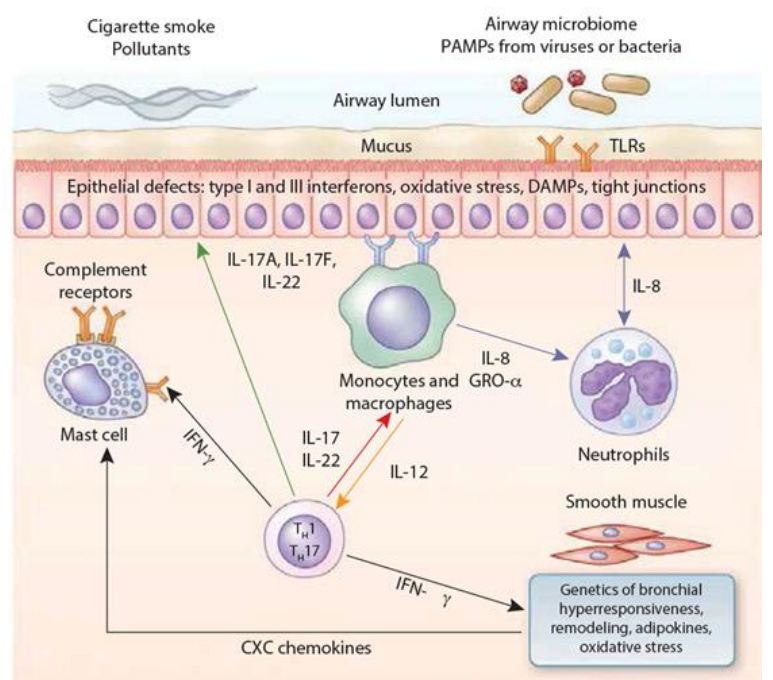

Figure 3: Bronchial asthma phenotypes (Non-Th2 asthma phenotype)(Wenzel, 2006). Non-Th2: Non T helper cells type 2

\section{Phenotypes of asthma}

A phenotype represents the outward manifestation of an individual's underlying genetics, and may change over time in response to new environments. Disease phenotype may significantly affect choice of diagnostic tests and long-term prognosis, and most importantly predict responsiveness to specific pharmacotherapies (Siroux et al., 2011).

\section{Phenotyping Based Upon Inflammatory Biomarkers}

Inflammatory cells. Blood eosinophilia is identified in many patients with asthma, and markedly elevated blood eosinophil counts have been associated with a severe form of late-onset asthma (Van Veen et al., 2009). T helper $2\left(\mathrm{Th}_{2}\right)$ cells are thought to be largely responsible for stimulating eosinophilic infiltration into the airways, and the principal cytokines involved in the influx of eosinophils includes interleukin-4 (IL-4), IL-5, and IL-13. While IL-5 is instrumental in the differentiation, survival, and chemotaxis of eosinophils (Takatsu., 2011), IL-4 and IL13 both up regulate adhesion molecules (e.g., vascular cell adhesion molecule 1 ( VCAM-1) and facilitate the entry of eosinophils into tissue sites of inflammation, Therefore, identification of blood or sputum eosinophils is usually evidence of $\mathrm{Th}_{2}$-type inflammation in the lungs. (Luzina et al., 2012).

Proteins. $T h_{2}$ cytokines are generally not detectable in the blood stream of patients with asthma and are difficult to measure in sputum samples. While they can be detected 
from bronchial washings, this is not a practical approach to determine the molecular phenotype of a patient. Recently investigators have sought to identify bronchial-derived proteins that are associated with $\mathrm{Th}_{2}$ airway inflammation, which may then be used as markers for that phenotype. In a recent study of mild, corticosteroid-naive asthmatics, investigators analyzed airway epithelial brushings for the expression of three genes up regulated by the $\mathrm{Th}_{2}$ cytokine interleukin-13 (IL-13) (Woodruff et al., 2009).

Importantly, subjects who had elevated levels of these $\mathrm{Th}_{2}$-associated proteins had better responses to inhaled corticosteroids (ICS) therapy, whereas the $\mathrm{Th}_{2}$-low group did not, suggesting that this distinction is predictive of corticosteroidresponsiveness. (Woodruff et al., 2009).

These observations have been extended to a new experimental therapy for asthma. Lebrikizumab, a humanized monoclonal antibody directed against IL-13, was studied in a randomized, placebocontrolled trial of patients with poorlycontrolled asthma despite treatment with ICS or ICS/long-acting beta-agonist (LABA) combination (Corren et al., 2011).

Exhaled nitric oxide. Nitric oxide (NO) is produced by all tissues in the body, including the lung. Exhaled NO has been shown to correlate moderately with bronchial and blood eosinophilia in patients with asthma (Jones et al., 2001). NO is produced by the enzyme NO synthase, which is under the direct control of the $\mathrm{Th}_{2}$ cytokine IL-13 ,Elevated concentrations of exhaled NO therefore reflect increased IL-13 activity, and indicate the presence of a $\mathrm{Th}_{2}$ phenotype. Exhaled NO has been shown to predict the possibility of steroid responsiveness more consistently than spirometry, bronchodilator response, peak flow variation, or airway hyper-responsiveness to inhaled methacholine (Chibana et al., 2008).

Over the past decade, understanding of asthma has changed considerably, with better insights into its heterogeneity. Consequently, treatment has changed from being based on a 'one-size-fits-all' model to a more patientcentred or personalized approach(Tamblyn et al., 2015).

\section{Non pharmacological management of}

\section{Asthma}

Central to this development is supported selfmanagement and provision of an individualized written asthma action plan, referred to guidelines as the co-management of asthma(Levy, 2014). This approach ensures that interventions are tailored to the needs of patients, such as prioritizing minimal absences from school and work, creation of a supportive partnership with their doctor, family support and use of the appropriate drug regimen and inhaler devices. Such co-management plans should provide the best quality of life (QOL) through minimizing disease symptoms and abolishing disease exacerbations(Toelle \& Ram, 2004). As far as is possible, drug treatment should only be initiated after removal of the stimuli known to exacerbate the disease.

\section{Management of bronchial Asthma in} specific populations

This management situation becomes more complex in children, especially in those $<5$ 
years of age, as many children who present with asthma symptoms have one of the various wheezing syndromes that, compared with asthma, are less likely to persist into adult life and do not require treatment with ICSs(Depner et al., 2014). Unfortunately, the clinician has few tools available to determine which children are likely to have or develop persistent asthma and therefore benefit from early treatment.

In adults, GINA guidelines, which were updated in 2020, have provided sound recommendations to be used worldwide (GINA, 2020). However, health services and treatment facilities, including the availability of drugs, differ between countries, and these disparities need to be taken into account when constructing action plans for asthma(Roberts et al., 2009).

\section{Adults}

\section{Standard asthma management}

Asthma guidelines such as those provided by GINA(Postma \& Rabe, 2015), the US National Asthma Education and Prevention Program(Mensah et al., 2018)and the British Thoracic Society(Perlitz, 2016) classify asthma by severity and extent of disease control. Asthma severity is assessed retrospectively from the level of treatment required to control symptoms and exacerbations. It can be assessed once the patient has been on controller treatment for several months and, if appropriate, treatment step down has been attempted to find the patient's minimum effective level of treatment. Asthma severity is not a static feature and may change over months or years.
Asthma severity can be assessed when the patient has been on regular controller treatment for several months (Table 1).

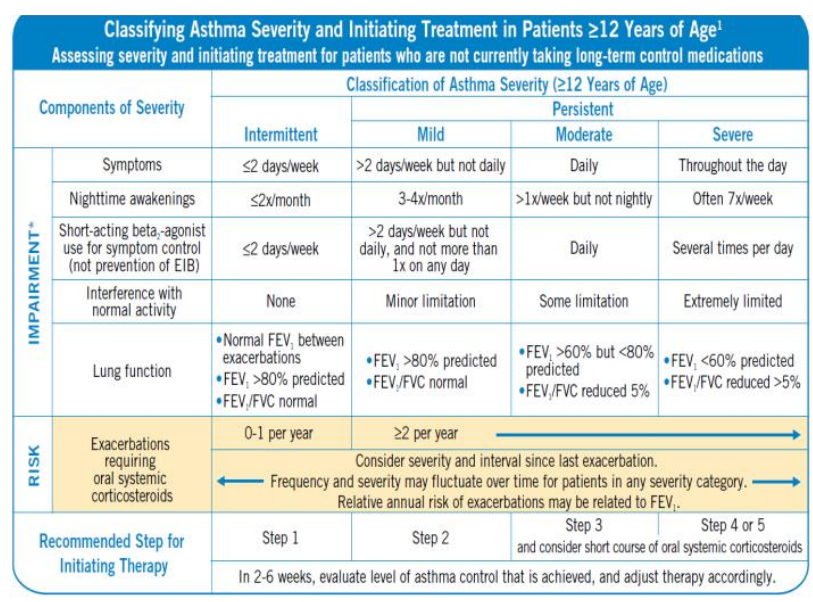

"Normal FEV,JFVC: $8-19$ yr: $85 \%$ |20-39 vr: $80 \%$ | $40-59$ yr: $75 \%$ |60-80 vr: $70 \%$

Table (1): Assessing asthma severity (NHLBI Guidelines, 2020). NHLBI: National Heart, Lung, and Blood Institute

Assessing asthma severity (NHLBI Guidelines, 2020).

- Mild asthma is asthma that is well controlled with Step 1 or Step 2 treatment i,e. with as-needed reliever medication alone, or with low-intensity controller treatment such as low dose ICS, leukotriene receptor antagonists or chromones.

- Moderate asthma is asthma that is well controlled with Step 3 treatment e.g. low dose ICS/LABA.

Severe asthma is asthma that requires Step 4 or 5 treatment e.g. high-dose ICS/LABA(GINA., 2020). This classification is done in 4 or 5 steps that are used to assess the use of controller drugs, such as inhaled ICSs, LABAs, LTRAs and, for the most severe disease, the IgE-specific monoclonal antibody omalizumab (Figure 4). 


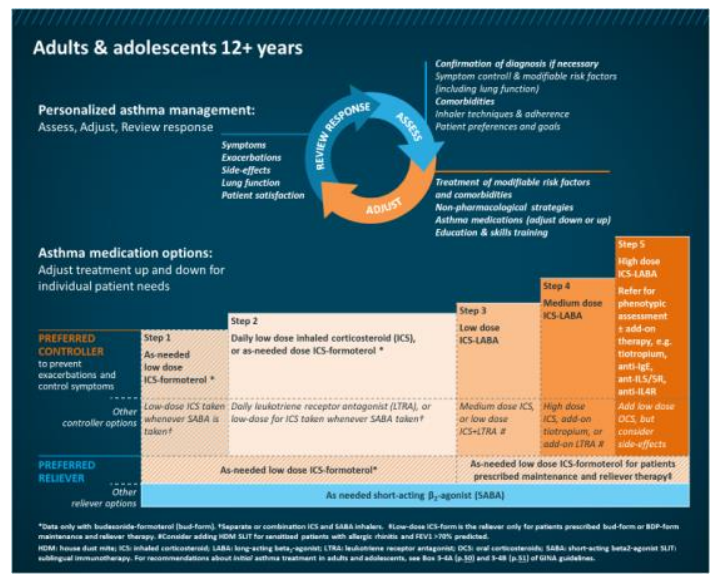

Figure 4: Stepping approach for asthma management in adults (GINA, 2020). GINA: Global Initiative for Asthma

By starting ICSs as a step one of the management plan and scaling controller therapy up in a stepwise manner, dependency on inhaled SABAs for symptom relief has been reduced, exacerbations prevented, asthma-related mortality reduced and QOL improved in the majority of patients with asthma. Combination of ICS-LABA therapy in moderate-to-severe asthma has achieved considerable success, as omalizumab in severe allergic asthma. Moreover, maintenance and rescue therapy with the combination of ICS and rapidly acting LABA (formoterol) has shown beneficial effects when used as maintenance and reliever treatment in adult patients with asthma(Papi et al., 2013). In those patients who remain symptomatic despite taking an ICS-LABA combination, adding a long-acting anti-muscarinic antagonist is beneficial(Lipworth, 2014). Inhaled drugs are most frequently used on demand or twice daily. Novel ultra-long-acting bronchodilators have been developed to be used once daily(Khan \& Ramos, 2020) but their effectiveness is yet to be fully evaluated. Despite the availability of a wide range of controller and reliever therapies, uncontrolled asthma remains a challenge. This problem reflects the need for new therapeutic options, especially as the number of deaths due to asthma has been reduced drastically since the introduction of anti-inflammatory treatments but, importantly, significant asthma-related mortality persists. In brief, currently experts recommend introducing anti-inflammatory treatment at the very initiation of asthma therapy, i.e., all adults and adolescents with mild asthma should receive low-dose inhaled corticosteroids (ICS) either for symptomdriven use or as a regular daily medication to reduce the risk of serious exacerbations. The withdrawal of the recommendation for ondemand short-acting $\beta 2$ agonists (SABA) as monotherapy as the first step of asthma treatment and the introduction/addition of symptom-driven ICS treatment on the first/second step of asthma therapy is the major paradigm shift from the previous GINA report.

The main goal of these changes is to reduce the risk of serious asthma exacerbations and asthma-related deaths in the population of patients with mild asthma. It has been widely known that SABA medications, while they provide quick relief from asthma symptoms, provide no anti-inflammatory effects and therefore do not treat the underlying cause of airway constriction. Consequently, when used alone, SABA treatments do not prevent severe exacerbations. Moreover, their regular or frequent use even increases the risk of nearfatal and fatal asthma attacks (GINA, 2020). Figure (5) shows that treatment should be based on both current control of a patient's asthma and reduction of future asthma risk. 


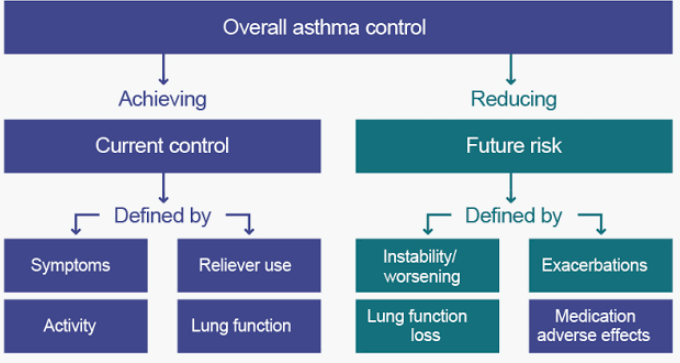

Figure 5: Overall goals of asthma management. Asthma management should aim to both control the current symptoms of asthma and reduce the risk of future adverse outcomes for patients. Adapted with permission from REF. 256, Elsevier.

Meta-analysis study compared methods for preventing severe disease exacerbations(Loymans et al., 2014) found that both combined maintenance and reliever treatment and combined fixed-dose treatment with ICSs and a LABA performed equally and were ranked first for effectiveness.

All other treatment strategies that used ICSs with another agent, whether by single or separate inhalers, tended to perform better than low-dose ICSs, but with no significant difference. In patients sensitized to a single allergen, for instance allergen Fel dI from cats or pectate lyase 1 (also known as antigen Amb a I) from ragweed, subcutaneous allergen immunotherapy is an option(Abramson et al., 2010). The effect of sublingual immunotherapy on asthma is still being evaluated, A recent study supports SLIT as an effective treatment for Immunomodulation in mild allergic asthmatics besides it gives us significant information regarding the safety and efficacy of SLIT in such patients. (Beigh et al., 2021).

Before deciding whether to start a new treatment or change treatment, health practitioners should reconsider whether there are any factors that are modifiable. These include incorrect use of an inhaler, active smoking or passive smoke exposure, obesity, rhinitis, sinusitis, diabetes mellitus, gastroesophageal reflux, anxiety and depression, low vitamin D status, limited language proficiency, absence of specialty care, lack of an asthma action plan and lack of selfmanagement education. Special consideration also needs to be given to managing asthma in pregnancy(Kelly et al., 2015).

Many factors should be considered during study design for efficient management of asthma. For example, they need to ensure that their findings have applicability for various settings and patient populations and that they have a patient-centred focus, such as that taken in pragmatic comparative effectiveness studies(de Llano et al., 2021). Nonetheless, although there is an ongoing need for further research in some areas, the evidence base in support of patient-centred and co-management approaches to asthma is strong(Ödling, 2021).

\section{Alternative therapeutic approaches}

Cluster analyses have identified subtypes of asthma, one of which is severe asthma that is unresponsive to ICS and oral corticosteroid treatment(Hinks et al., 2015). Despite extensive research, the underlying pathobiology of severe asthma has not been established. Nonetheless the aetiology of severe asthma is likely to be heterogeneous rather than based on a single unifying process (Figure 2). As a result of increased awareness of this heterogeneity, the identification of appropriate biomarkers in individual patients with asthma is becoming crucial in guiding the use of therapies that target the specific causative pathways or endotypes of asthma(Hambly \& Nair, 2014). Individual T2-type cytokine biologics that target the 
IL-4-IL-13, IL-5 and TSLP pathways and IgE itself are promising treatment options for severe disease, especially when used with biomarkers such as sputum and blood eosinophil numbers, FeNO, serum periostin levels and total IgE levels to differentiate 'responders' from 'non-responders'. Blockade of a single pathway has clear clinical benefits and few associated adverse effects. However, whereas this strategy leads to improvement in some asthma outcomes, such as a reduction in asthma exacerbations produced with IL-5-specific therapy, outcomes for other measures, such as lung function and hyperresponsiveness, are less favorable. As a result, single pathway blockade has only partial efficacy(Pavord et al., 2012). Additional research is needed to define how such agents should be used in a stratified or personalized approach to management. The same is true for pharmacogenomics, in which singlenucleotide polymorphisms in genes contribute to treatment responsiveness.

The proportion of phenotypic variability accounted for genetic variation (heritability) is estimated to be $28.5 \%$ for bronchodilator responsiveness and $50 \%$ for lung function(Lima, 2014). For example, the Arg16 allele of the gene encoding the $\beta 2$-adrenergic receptor has been shown to associate with worsening of asthma when adult with the disease receive continuous SABA or LABA monotherapy(Manoharan et al., 2015). This and other variants of the $\beta 2$-adrenergic receptor have different effects on the disease in different ethnic populations(Ortega et al., 2014). Polymorphisms also influence responsiveness to ICSs and LTRAs and necessitat further study(Meyers et al., 2014).
Bronchial thermoplasty, delivered by the AlairTM System, is a treatment for severe asthma that was approved by the US FDA in 2010 (Figure 6).

\section{The Alair ${ }^{\mathrm{TM}}$ System}
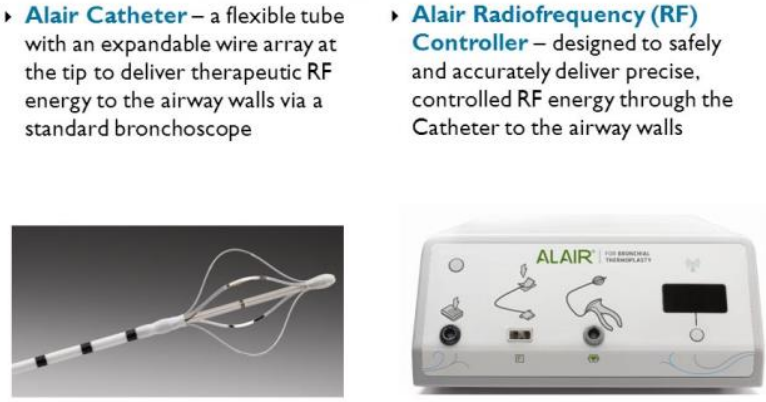

Figure (6): Alair ${ }^{\mathrm{TM}}$ System.

This treatment involves the delivery of controlled, therapeutic radiofrequency energy to the airway wall to heat the tissue and thereby reduce the amount of smooth muscle in the airway wall(Miller \& Murgu, 2014). This procedure causes epithelial injury followed by regeneration of the epithelium, blood vessels, mucosa and nerves but not airway smooth muscle(Castro et al., 2015). Indeed, there is preliminary evidence that this procedure is able to reduce airway smooth muscle mass in patients with severe asthma(Pretolani et al., 2014). Although bronchial thermoplasty is an exciting development for managing some types of severe asthma, its place in management guidelines is still being evaluated (W. Chen et al., 2021).

\section{Children}

Although early treatment reduces asthma symptoms in those at high risk of developing persistent asthma, there is no evidence that 
early treatment decreases the risk of subsequent asthma or alters its natural history(Guilbert et al., 2006). In addition, with the exceptions of treatment with omalizumab for children $>12$ years of age who have severe atopic asthma that is not controlled by maximal conventional therapy(Busse et al., 2011) and treatment with oral montelukast (a cysteinyl LTRA) for exercise-induced asthma(Wasfi et al., 2011), so far, there is little evidence that 'phenotype-specific' therapy is helpful in children(Schultz \& Brand, 2012). Treatment of asthma in schoolaged children is perhaps the most straightforward, with most patients responding to simple first-line therapy that forms the basis of most asthma management plans. If first-line therapy is not successful, there is no single 'best' add-on therapy for all children. Thus, if the first add-on is not sufficient, it should be stopped and an alternative therapy of a different drug class tried in its place(Lemanske Jr et al., 2010).

The diagnosis and treatment of asthma in infants and preschool-aged children is much more problematic than it is for older children. As outlined earlier, although most severe childhood asthma starts early in life, the majority of infants and young children who have wheezing episodes do not progress to persistent asthma(Martinez, 2009). A further problem arises with the apparent lack of clinical or physiological response to bronchodilators in infants and young children with established asthma-related risk factors that predict long-term outcomes(Fd, 2013). The aim of asthma management at all ages is to achieve good clinical control for as long as possible. Young children with persistent symptoms should be managed in a similar manner to that of older children with persistent symptoms. As pointed out in the GINA guidelines, for children $\leq 5$ years of age(Al-Moamary et al., 2021), a combination of increased daytime cough, daytime wheeze and night-time use of an inhaled SABA is a strong predictor of acute exacerbations in these children. Inhaled medications are the cornerstone of asthma management in younger children; however, substantial importance must be placed on the ability of the child to use the inhalation device. The use of ICSs as first-line management for children with persistent symptoms is supported by placebo-controlled clinical trials(Van Asperen et al., 2011). In contrast with adults, there is no evidence for the use of combination ICSLABA therapy in this age group, with the GINA guidelines specifically advising against this in children $\leq 5$ years of age.

The treatment of intermittent, usually viralinduced, symptoms in young children is more controversial. As discussed earlier, the use of ICSs or the LTRA montelukast as maintenance therapy does not reduce the frequency of acute intermittent symptoms in young children. Montelukast but not ICSs(Arakawa et al., 2020) or oral corticosteroids(Beigelman et al., 2013) given as a short-course treatment at the onset of symptoms can reduce the severity and duration of asthma symptoms, but do not reduce the need for additional medication or hospitalization. There is no justification for using a LTRA in infants(Vogelberg et al., 2020). Many young children can be treated with SABAs alone to relieve symptoms (Figure 7). 
Vol. 30, Issue 1, pp. 33- 49

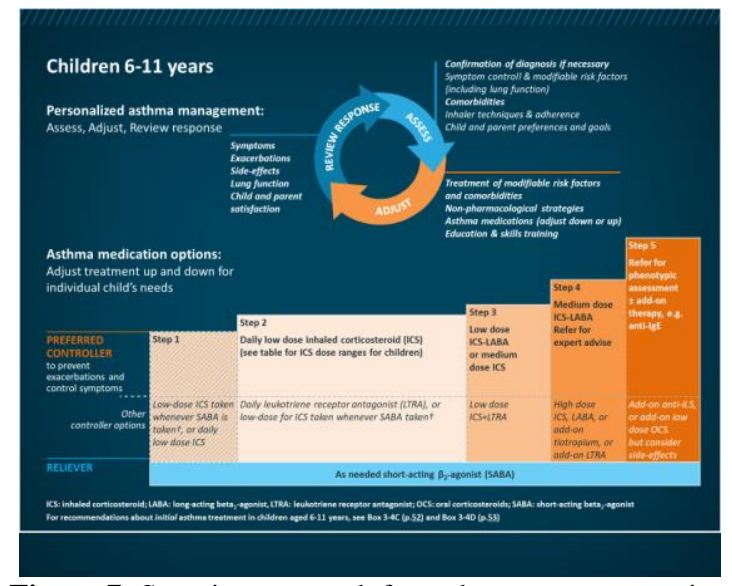

Figure 7: Stepping approach for asthma management in children (GINA, 2020). GINA: Global Initiative for Asthma

\section{Quality of life}

For most patients with asthma, life expectancy should not differ from the general population. Thus, treatment of asthma is primarily focused on improving the day-to-day symptoms of the patient, preventing exacerbations and generally improving their QOL (Figure 4). Indeed, GINA (GINA, 2020) identifies asthma control as the main outcome of asthma management. Asthma control incorporates level of symptoms, number and severity of exacerbations, as well as lung function. The effect of these factors on patients' activities and daily living is generally referred to as a patient's QOL. To address this more holistic approach, patientreported outcome measures are becoming more attractive in the assessment of treatment success(Worth et al., 2014). These are typically short, self-completed questionnaires, most commonly used to measure the health status or health-related QOL of a patient before and after an intervention. The concept that PROMs are necessary to assess the impact of asthma treatment has contributed to their increasing use in clinical practice. The PROMs generally used for the assessment of
ISSN (on-line) 2356_9786

asthma are the asthma QOL questionnaire (AQLQ), the paediatric version of the AQLQ (PAQLQ), the Asthma Control Test (ACT) and the Asthma Control Questionnaire (ACQ)(Juniper \& Styles, 2018). The ACT and ACQ focus on symptoms and functional status rather than how these affect the patient's personal perceptions of the effect of asthma on their day-to-day QOL. However, these outcomes are intimately related as studies show strong correlations between the level of asthma control and QOL, even when controlling for disease severity(Chen et al., 2007).

QOL in patients with asthma is likely to be affected by various factors and co-morbidities associated with asthma, including asthma control (even when controlling for asthma severity), duration of disease and the concurrent need for chronic therapies, frequent exacerbations, obesity or weight gain and psychosocial factors(Haselkorn et al., 2009). In addition, sex and socioeconomic factors, as well as co-morbidities such as gastroesophageal reflux and rhinosinusitis also probably have a role in determining QOL in patients with asthma. These co-morbidities are particularly prevalent in more-severe asthma. Patients with more-severe asthma experience an increase in symptom severity, more frequent and severe exacerbations and more co-morbidity, all of which contribute to an overall poor QOL.

Treatment with ICSs, usually with SABAs or ICSs in combination with a LABA, montelukast or omalizumab have all been reported to improve QOL, with varying effects on asthma control, when compared with a placebo. Interestingly, not all therapies affect these parameters in the same manner. 
For instance, although IgE-specific treatment improves exacerbations in patients with moresevere asthma, the mean improvement in QOL as measured by the AQLQ, while substantial, does not achieve the 0.5 points threshold change for clinical significance on the 7-point scale of this questionnaire(Hanania et al., 2011). The intensity of the intervention also seems to influence the magnitude of improvement in the AQLQ. This improvement is demonstrated by the invasive treatment bronchial thermoplasty; however, the difference in improvement between active and sham thermoplasty also did not achieve clinical significance(Egan, 2012). Finally, it should be recognized that the mere label of asthma as a chronic disease, with lifelong required treatment and daily confrontation with the disease, even though controlled to some extent, might affect the QOL of an individual with asthma considerably, irrespective of disease severity(Earnshaw \& Quinn, 2012). Hence, all efforts should be made to prevent disease chronicity.

\section{Conclusion}

Asthma is an important chronic disease resulting in clinically significant morbidity, missed days of work or school, substantial costs for emergency care and hospitalization, and sometimes, death. Although substantial progress has been made in understanding of asthma mechanisms and epidemiology, these are only just being translated into novel approaches for disease management. However, the prevention of asthma in at-risk infants and cure of the fully developed disease seem distant goals. All current therapies are still based on damping down airway inflammation and on relieving airway obstruction. To make further progress and recognizing that the most of the disease begins early in life, we need to understand what the genetic, prenatal, maternal and earlylife environmental factors are that initiate asthma or at least render particular infants more susceptible to it. The discovery of gene functions through ecological exposure by epigenetics is critical.

\section{References}

Abramson, M. J., Puy, R. M., \& Weiner, J. M. (2010). Injection allergen immunotherapy for asthma. Cochrane Database of Systematic Reviews, 8.

Al-Moamary, M. S., Alhaider, S. A., Alangari, A. A., Idrees, M. M., Zeitouni, M. O., Al Ghobain, M. O., Alanazi, A. F., Al-Harbi, A. S., Yousef, A. A., \& Alorainy, H. S. (2021). The Saudi Initiative for Asthma-2021 Update: Guidelines for the diagnosis and management of asthma in adults and children. Annals of Thoracic Medicine, 16(1), 4.

Amelink, M., de Groot, J. C., de Nijs, S. B., Lutter, R., Zwinderman, A. H., Sterk, P. J., ten Brinke, A., \& Bel, E. H. (2013). Severe adult-onset asthma: A distinct phenotype. Journal of Allergy and Clinical Immunology, 132(2), 336-341.

Arakawa, H., Adachi, Y., Ebisawa, M., \& Fujisawa, T. (2020). Japanese guidelines for childhood asthma 2020. Allergology International, 69(3), 314-330.

Beigelman, A., King, T. S., Mauger, D., Zeiger, R. S., Strunk, R. C., Kelly, H. W., Martinez, F. D., Lemanske Jr, R. F., Rivera-Spoljaric, K., \& Jackson, D. J. (2013). Do oral corticosteroids reduce the 
severity of acute lower respiratory tract illnesses in preschool children with recurrent wheezing? Journal of Allergy and Clinical Immunology, 131(6), 15181525 .

Beigh, A. H., Rasool, R., Kawoosa, F., Rashid, R., Andrabi, K. I., \& Qureshi, T. (2021). Improved pulmonary function test (PFT) after 1 one year of Sublingual Immunotherapy (SLIT) in unison with pharmacotherapy in mild allergic asthmatics. Immunology Letters, 230, 3641.

Busse, W. W., Morgan, W. J., Gergen, P. J., Mitchell, H. E., Gern, J. E., Liu, A. H., Gruchalla, R. S., Kattan, M., Teach, S. J., \& Pongracic, J. A. (2011). Randomized trial of omalizumab (anti-IgE) for asthma in inner-city children. New England Journal of Medicine, 364(11), 10051015.

Castro, M., Cox, G., Wechsler, M. E., \& Niven, R. M. (2015). Bronchial thermoplasty: Ready for prime time-the evidence is there! Chest, 147(2), e73e74.

Chen, H., Gould, M. K., Blanc, P. D., Miller, D. P., Kamath, T. V., Lee, J. H., Sullivan, S. D., \& TENOR Study Group. (2007). Asthma control, severity, and quality of life: Quantifying the effect of uncontrolled disease. Journal of Allergy and Clinical Immunology, 120(2), 396402.

Chen, W., Chen, S., \& Huang, Y. (2021). Induction and maintenance of procedural sedation in adults: Focus on remimazolam injection. Expert Review of Clinical Pharmacology.

Chibana K., Trudeau J.B., Mustovich A.T.,et al ., (2008): IL-13 induced increases in nitrite levels are primarily driven by increases in inducible nitric oxide synthase as compared with effects on arginases in human primary bronchial epithelial cells. Clin Exp Allergy; 38:936946.

Corren J, Lemanske R.F, Hanania N.A,et al ., (2011): Lebrikizumab treatment in adults with asthma. N Engl J Med;

365(12):1088-1098.

Custovic, A. (2015). To what extent is allergen exposure a risk factor for the development of allergic disease? Clinical \& Experimental Allergy, 45(1), 54-62.

Custovic, A., Johnston, S., Pavord, I., Gaga, M., Fabbri, L., Bel, E., Le Souëf, P., Lötvall, J., Demoly, P., \& Akdis, C. (2013). EAACI position statement on asthma exacerbations and severe asthma. Allergy, 68(12), 1520-1531.

de Llano, L. P., Rivas, D. D., Cid, N. B., \& Robles, I. M. (2021). Phenotype-Guided Asthma Therapy: An Alternative Approach to Guidelines. Journal of Asthma and Allergy, 14, 207.

Depner, M., Fuchs, O., Genuneit, J., Karvonen, A. M., Hyvärinen, A., Kaulek, V., Roduit, C., Weber, J., Schaub, B., \& Lauener, R. (2014). Clinical and epidemiologic phenotypes of childhood asthma. American Journal of Respiratory and Critical Care Medicine, 189(2), 129138.

Earnshaw, V. A., \& Quinn, D. M. (2012). The impact of stigma in healthcare on people living with chronic illnesses. Journal of Health Psychology, 17(2), 157-168.

Egan, J. J. (2012). Emerging bronchoscopic therapies for stage IV advanced emphysema. Chest, 142(3), 552-553. 
Zagazig J. Pharm. Sci. Jun, 2021

Vol. 30, Issue 1, pp. 33- 49

Fd, M. (2013). Vercelli D. Asthma. Lancet, 382(1).

Fu, L., Freishtat, R. J., Gordish-Dressman, H., Teach, S. J., Resca, L., Hoffman, E. P., \& Wang, Z. (2014). Natural progression of childhood asthma symptoms and strong influence of sex and puberty. Annals of the American Thoracic Society, 11(6), 939-944.

GINA 2020. Global Initiative for Asthma. Strategy for Asthma Management and Prevention.

Guilbert, T. W., Morgan, W. J., Zeiger, R. S., Mauger, D. T., Boehmer, S. J., Szefler, S. J., Bacharier, L. B., Lemanske Jr, R. F., Strunk, R. C., \& Allen, D. B. (2006). Long-term inhaled corticosteroids in preschool children at high risk for asthma. New England Journal of Medicine, 354(19), 1985-1997.

Hambly, N., \& Nair, P. (2014). Monoclonal antibodies for the treatment of refractory asthma. Current Opinion in Pulmonary Medicine, 20(1), 87-94.

Hanania, N. A., Alpan, O., Hamilos, D. L., Condemi, J. J., Reyes-Rivera, I., Zhu, J., Rosen, K. E., Eisner, M. D., Wong, D. A., \& Busse, W. (2011). Omalizumab in severe allergic asthma inadequately controlled with standard therapy: A randomized trial. Annals of Internal Medicine, 154(9), 573-582.

Haselkorn, T., Zeiger, R. S., Chipps, B. E., Mink, D. R., Szefler, S. J., Simons, F. E. R., Massanari, M., \& Fish, J. E. (2009). Recent asthma exacerbations predict future exacerbations in children with severe or difficult-to-treat asthma. Journal of Allergy and Clinical Immunology, 124(5), 921-927.

Hinks, T. S., Zhou, X., Staples, K. J., Dimitrov, B. D., Manta, A., Petrossian,
ISSN 1110-5089

ISSN (on-line) 2356_9786

T., Lum, P. Y., Smith, C. G., Ward, J. A., \& Howarth, P. H. (2015). Innate and adaptive $\mathrm{T}$ cells in asthmatic patients: Relationship to severity and disease mechanisms. Journal of Allergy and Clinical Immunology, 136(2), 323-333.

Jones S.L, Kittelson J, Cowan J.O, et al., (2001): The predictive value of exhaled nitric oxide measurements in assessing changes in asthma control. Am J Respir Crit Care Med; 164:738-743.

Juniper, E., \& Styles, J. (2018). Measurement of health-related quality of life and asthma control. Quoltech [Online].

Kelly, W., Massoumi, A., \& Lazarus, A. (2015). Asthma in pregnancy: Physiology, diagnosis, and management. Postgraduate Medicine, 127(4), 349-358.

Khan, M. F., \& Ramos, L. (2020). Drugs Affecting Adrenergic System. Medicinal Chemistry of Drugs Affecting the Nervous System, 2, 59-108.

Lange, P., Parner, J., Vestbo, J., Schnohr, P., \& Jensen, G. (1998). A 15-year follow-up study of ventilatory function in adults with asthma. New England Journal of Medicine, 339(17), 1194-1200.

Ledford, D. K., \& Lockey, R. F. (2013). Asthma and comorbidities. Current Opinion in Allergy and Clinical Immunology, 13(1), 78-86.

Lemanske Jr, R. F., Mauger, D. T., Sorkness, C. A., Jackson, D. J., Boehmer, S. J., Martinez, F. D., Strunk, R. C., Szefler, S. J., Zeiger, R. S., \& Bacharier, L. B. (2010). Step-up therapy for children with uncontrolled asthma receiving inhaled corticosteroids. New England Journal of Medicine, 362(11), 975-985. 
Levy, M. L. (2014). Preventing avoidable asthma deaths. Practitioner, 258(1774), 27-31.

Lima, J. J. (2014). Do genetic polymorphisms alter patient response to inhaled bronchodilators? Expert Opinion on Drug Metabolism \& Toxicology, 10(9), 12311240 .

Lipworth, B. J. (2014). Emerging role of long acting muscarinic antagonists for asthma. British Journal of Clinical Pharmacology, 77(1), 55-62.

Loymans, R. J., Gemperli, A., Cohen, J., Rubinstein, S. M., Sterk, P. J., Reddel, H. K., Jüni, P., \& ter Riet, G. (2014). Comparative effectiveness of long term drug treatment strategies to prevent asthma exacerbations: Network metaanalysis. Bmj, 348 .

Luzina I.G., Keegan A.D., Heller N.M.,et al., (2012): Regulation of inflammation by interleukin-4: a review of "alternatives. J Leukoc Biol; 92(4):753-764.

Manoharan, A., Griffin, B., Lipworth, J., Berg, J., Andrew, N., Jackson, C., \& Lipworth, B. (2015). B2-adrenergic receptor Gly16Arg polymorphism and impaired asthma control in corticosteroidtreated asthmatic adults. Annals of Allergy, Asthma \& Immunology, 114(5), 421-423.

Martinez, F. (2009). The connection between early life wheezing and subsequent asthma: The viral march. Allergologia et Immunopathologia, 37(5), 249-251.

Mensah, G. A., Kiley, J. P., \& Gibbons, G. H. (2018). Generating evidence to inform an update of asthma clinical practice guidelines: Perspectives from the National Heart, Lung, and Blood
ISSN (on-line) 2356_9786

Institute. Journal of Allergy and Clinical Immunology, 142(3), 744-748.

Meyers, D. A., Bleecker, E. R., Holloway, J. W., \& Holgate, S. T. (2014). Asthma genetics and personalised medicine. The Lancet Respiratory Medicine, 2(5), 405415.

Miller, R. J., \& Murgu, S. D. (2014). Interventional pulmonology for asthma and emphysema: Bronchial thermoplasty and bronchoscopic lung volume reduction. 35(06), 655-670.

Moore, W. C., Meyers, D. A., Wenzel, S. E., Teague, W. G., Li, H., Li, X., D’Agostino Jr, R., Castro, M., Curran-Everett, D., \& Fitzpatrick, A. M. (2010). Identification of asthma phenotypes using cluster analysis in the Severe Asthma Research Program. American Journal of Respiratory and Critical Care Medicine, 181(4), 315-323.

Murray, C. S., Woodcock, A., Langley, S. J., Morris, J., Custovic, A., \& IFWIN Study Team. (2006). Secondary prevention of asthma by the use of Inhaled Fluticasone propionate in Wheezy INfants (IFWIN): Double-blind, randomised, controlled study. The Lancet, 368(9537), 754-762.

National Heart, Lung, and Blood Institute., (2008): Global Strategy for Asthma

Management and Prevention. NIH

Publication.

Ödling, M. (2021). Bridging the gap in asthma management among adolescents and young adults.

Ortega, V. E., Hawkins, G. A., Moore, W. C., Hastie, A. T., Ampleford, E. J., Busse, W. W., Castro, M., Chardon, D., Erzurum, S. C., \& Israel, E. (2014). Effect of rare variants in ADRB2 on risk of severe exacerbations and symptom control 
during longacting $\beta$ agonist treatment in a multiethnic asthma population: A genetic study. The Lancet Respiratory Medicine, 2(3), 204-213.

Papi, A., Corradi, M., Pigeon-Francisco, C., Baronio, R., Siergiejko, Z., Petruzzelli, S., Fabbri, L. M., \& Rabe, K. F. (2013). Beclometasone-formoterol as maintenance and reliever treatment in patients with asthma: A double-blind, randomised controlled trial. The Lancet Respiratory Medicine, 1(1), 23-31.

Pavord, I. D., Korn, S., Howarth, P., Bleecker, E. R., Buhl, R., Keene, O. N., Ortega, H., \& Chanez, P. (2012). Mepolizumab for severe eosinophilic asthma (DREAM): A multicentre, double-blind, placebocontrolled trial. The Lancet, 380(9842), 651-659.

Perlitz, W.-D. (2016). Zur empirischen Ermittlung von evidenzbasiertem Patientennutzen in der Hausarztzentrierten Versorgung ( $\mathrm{HzV})$. Nomos Verlagsgesellschaft $\mathrm{mbH} \& \mathrm{Co}$. $\mathrm{KG}$.

Porsbjerg, C., Lange, P., \& Ulrik, C. S. (2015). Lung function impairment increases with age of diagnosis in adult onset asthma. Respiratory Medicine, 109(7), 821-827.

Postma, D. S., \& Rabe, K. F. (2015). The asthma-COPD overlap syndrome. New England Journal of Medicine, 373(13), 1241-1249.

Pretolani, M., Dombret, M.-C., Thabut, G., Knap, D., Hamidi, F., Debray, M.-P., Taille, C., Chanez, P., \& Aubier, M. (2014). Reduction of airway smooth muscle mass by bronchial thermoplasty in patients with severe asthma. American Journal of Respiratory and Critical Care Medicine, 190(12), 1452-1454.
ISSN (on-line) 2356_9786

Roberts, N. J., Mohamed, Z., Wong, P.-S., Johnson, M., Loh, L.-C., \& Partridge, M. R. (2009). The development and comprehensibility of a pictorial asthma action plan. Patient Education and Counseling, 74(1), 12-18.

Schultz, A., \& Brand, P. L. (2012). Phenotype-directed treatment of preschool-aged children with recurrent wheeze. Journal of Paediatrics and Child Health, 48(2), E73-E78.

Siroux V., Basagaña X., Boudier A.,et al., (2011): Identifying adult asthma phenotypes using a clustering approach.

Eur Respir J 38(2):310-317.

Soyka, M. B., van de Veen, W., Holzmann, D., Akdis, M., \& Akdis, C. A. (2014). Scientific foundations of allergen-specific immunotherapy for allergic disease. Chest, 146(5), 1347-1357.

Takatsu K., (2011): Interleukin-5 and IL-5 receptor in health and diseases. Proc Jpn Acad Ser B Phys Biol Sci 87(8):463-485.

Tamblyn, R., Ernst, P., Winslade, N., Huang, A., Grad, R., Platt, R. W., Ahmed, S., Moraga, T., \& Eguale, T. (2015). Evaluating the impact of an integrated computer-based decision support with person-centered analytics for the management of asthma in primary care: A randomized controlled trial. Journal of the American Medical Informatics Association, 22(4), 773-783.

Toelle, B., \& Ram, F. S. (2004). Written individualised management plans for asthma in children and adults. Cochrane Database of Systematic Reviews, 1 .

Van Asperen, P. P., Mellis, C. M., Sly, P. D., \& Robertson, C. F. (2011). Evidencebased asthma management in children- 
What's new. Med J Aust, 194(8), 383384.

Van Veen I.H., Ten Brinke A., Gauw S.A.,et al., (2009): Consistency of sputum eosinophilia in difficult-to-treat asthma: a 5-year follow-up study. J Allergy Clin Immunol; 124:615-617.

Vogelberg, C., Goldstein, S., Graham, L., Kaplan, A., de la Hoz, A., \& Hamelmann, E. (2020). A comparison of tiotropium, long-acting $\beta$ 2-agonists and leukotriene receptor antagonists on lung function and exacerbations in paediatric patients with asthma. Respiratory Research, 21(1), 119.

Wasfi, Y. S., Kemp, J. P., Villarán, C., Massaad, R., Xin, W., Smugar, S. S., Knorr, B. A., \& George, P. (2011). Onset and duration of attenuation of exerciseinduced bronchoconstriction in children by single-dose of montelukast. 32(6), 453.
Woodruff P.G., Modrek B., Choy D.F.,et al., (2009): T-helper type 2-driven inflammation defines major subphenotypes of asthma. Am J Respir Crit Care Med; 180(5):388-395.

Worth, A., Hammersley, V., Knibb, R., Flokstra-de-Blok, B., DunnGalvin, A., Walker, S., Dubois, A. E., \& Sheikh, A. (2014). Patient-reported outcome measures for asthma: A systematic review. NPJ Primary Care Respiratory Medicine, 24(1), 1-8. 


\section{اتجاهات حديثه في علاج الربو الشعبي}

\section{اشرف السيد سليم، حنان محمد النحاس، احمد امين , احمد محمد جوده}

الربو الشعبي هو أكثر الأمراض الالتهابية المزمنة شيوعًا في الرئتين. بيتز ابد انتشار الربو في جميع

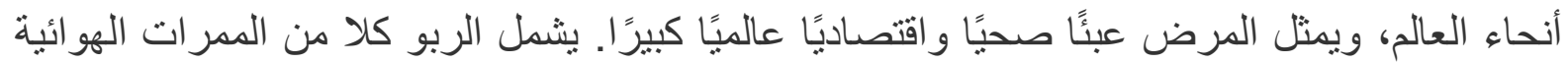
الكبيرة والصغيرة الموصلة للهواء، ويتصف الربو بمزيج من الالتهاب مع تغيير في شكل الجهاز

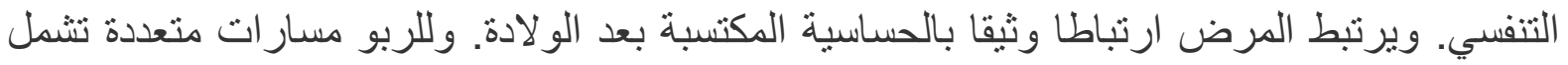
أزيزًا ناتجًا عن الفيروس وحساسية لمسببات الحساسية، و الذي يرتبط بآليات أساسية مختلفة (أو أنماط

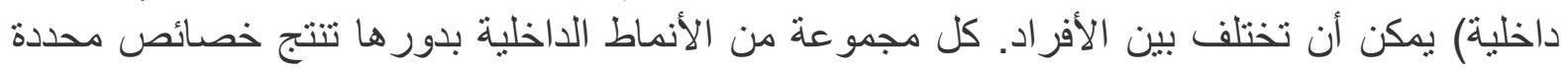

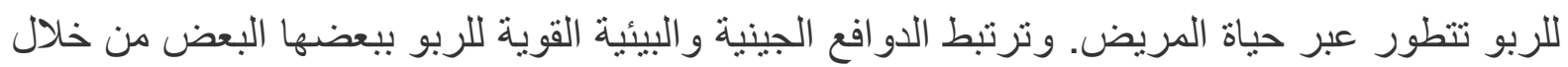
آليات جينية جديدة تعمل قبل الولادة وطو ال الطفولة. 